\title{
VIEWPOINT
}

\section{Heparin dose during percutaneous coronary intervention: how low dare we go?}

\section{G Niccoli, A P Banning}

Heart 2002;88:331-334

Despite dramatic advances in percutaneous coronary intervention, including coronary stents and potent antiplatelet agents, unfractionated heparin remains the standard procedural anticoagulant. Tradition and habit may have considerable influence over dose selection. A review of the role and dosage of heparin during $\mathrm{PCl}$ appears to be overdue

U nfractioned heparin (UFH) exerts its anticoagulant effect by potentiating the effects of antithrombin III upon factor Xa and thrombin. ${ }^{1}$ It has been used since the advent of percutaneous coronary intervention (PCI) to inhibit platelet rich thrombus formation, both at the site of balloon injury and upon angioplasty equipment. ${ }^{2}$ In vivo studies have confirmed dose dependent reduction in thrombin activity at the site of balloon injury following heparin administration, ${ }^{45}$ and clinical angioplasty studies have demonstrated reduction in coronary sinus fibrinopeptide A concentrations confirming effects of bolus heparin upon thrombin activity.

Unfortunately, the effect of bolus administration of heparin in any individual is not completely predictable. It is influenced by differences in body mass, the clinical scenario-particularly acute coronary syndromes which can increase heparin resistance-and concomitant use of other drugs, especially nitrates and thrombolytic agents. ${ }^{78}$ Its effect is also influenced by concentrations of platelet factor 4 and, unlike direct thrombin inhibitors, it is unable to inhibit clot bound thrombin. ${ }^{9}$ There is also an incidence of heparin induced thrombocytopenia which requires administration of alternative intravenous anticoagulants-either lepirudin or argatroban..$^{9-11}$ Despite these limitations, unfractionated heparin remains the standard anticoagulant for most PCI procedures.

The effect of UFH is monitored in the catheter laboratory using the activated clotting time (ACT) a simple, almost instantaneous and reliable method. Unfortunately, ACT does not correlate with any laboratory based assessment of the coagulation cascade as it only describes the propensity of whole blood to clot in a tube containing procoagulant. ${ }^{12}$ Hemochron and HemoTec devices are commonly used to measure ACT and the Hemochron ACT generally exceeds HemoTec ACT by up to $30 \%,{ }^{13}$ although considerable variability exists. ${ }^{14}{ }^{15}$ The activated partial thromboplastin time (aPTT) requires a specimen to be sent to the coagulation laboratory with an inevitable delay; unlike ACT, aPTT has limited
OX3 9DU, UK;

orh.anglox.nhs.uk accuracy when high or low concentrations of heparin are used. ${ }^{16}$ The heparin management test (HMT) may provide a more representative bedside test than ACT. ${ }^{17}$ Only a drop of blood is required and there appears to be a good correlation between ACT and HMT. At present these data are preliminary and ACT remains the current standard for monitoring heparin administration during PCI. Recent American College of Cardiology/American Heart Association guidelines recommend a target ACT value of 250-300 s (HemoTec) or 300-350 s (Hemochron). ${ }^{19}$

Tradition and habit may influence selection of heparin dose. $^{20}$ Much of the data regarding heparin administration during PCI were obtained before the introduction of coronary stenting and potent antiplatelet agents, and there are preliminary data suggesting that heparin itself could play a role in increasing platelet responsiveness. ${ }^{21}$ Increasingly a review of the role and dosage of heparin during PCI appears overdue.

\section{PLAIN OLD BALLOON ANGIOPLASTY (POBA)}

Acute vessel closure following balloon angioplasty occurred in up to $12 \%$ of balloon angioplasty cases. ${ }^{22}$ Acute occlusion was commonly related to the creation of semi-occlusive intimal flaps, slow non-laminar blood flow, and the development of luminal thrombus on highly thrombogenic exposed arterial media. ${ }^{23}$ Target values of ACT were originally derived from doses of heparin necessary to prevent thrombus in a cardiopulmonary bypass circuit with an optimum of at least $300 \mathrm{~s}^{24}{ }^{25}$ Retrospective clinical studies showed an inverse relation between ACT and early vessel closure-abrupt closure was more likely in patients with an ACT of less than $250 \mathrm{~s}$ at the onset of the procedure compared to patients undergoing uncomplicated angioplasty $(61 \% \mathrm{v}$ $27 \%, \mathrm{p}<0.0001) .{ }^{26}$ Similarly, Narins and colleagues documented an inverse linear relation between ACT and the probability of abrupt closure; this finding suggested that no threshold ACT was evident above which a further increase in the degree of anticoagulation would not be associated with a further reduction in the probability of abrupt closure, although clearly there was an increased risk of vascular haemorrhage. $^{27}$ Recent pooled analysis from

Abbreviations: $A C T$, activated clotting time; aPTT, activated partial thromboplastin time; HMT, heparin management test; $\mathrm{PCl}$, percutaneous coronary intervention; UFH, unfractioned heparin 
patients in the placebo arms of recent glycoprotein IIb/IIIa intervention trials demonstrated that higher ACTs in the range of 350-375 s were associated with the lowest event rate, but that a U shape relation existed between ischaemic events and ACT values. ${ }^{28}$ An ACT over $400 \mathrm{~s}$ was associated with an increased ischaemic risk, possibly reflecting a paradoxical prothrombotic effect of very high dose UFH. ${ }^{29}$

\section{THE STENT AND CLOPIDOGREL ERA: FIXED DOSE HEPARIN?}

Stents have revolutionised coronary intervention. Improved results at the site of angioplasty have been accompanied by development of new antiplatelet agents. Before high pressure stent deployment, oral anticoagulation, high dose heparin and potent platelet inhibition were all thought to be essential, but they inevitably resulted in high complication rates of vascular access sites. Using ticlopidine initially and later clopidogrel in combination with aspirin stents can be deployed safely without warfarin..$^{30} 31$

Improved predictability of the result at the site of PCI and concerns about complications of vascular access resulted in reduced anticoagulant regimens. Small initial studies suggested probable equivalence of weight adjusted ( $100 \mathrm{U} / \mathrm{kg}$ ) and high fixed dose heparin regimens (15-20000 U) with reduced vascular complications in the weight adjusted group. ${ }^{32}$ However, stent rates in these studies were only $30 \%$, and there was no clopidogrel. Subsequent prospective studies using low fixed dose UFH (5000 U) in patients undergoing elective percutaneous transluminal coronary angioplasty have documented high procedural success rates with low rates of abrupt closure and puncture site complications. ${ }^{33-35}$ A recent French registry reported encouraging data on 418 patients with angina using only $30 \mathrm{U} / \mathrm{kg}$ and a $77 \%$ stent rate. ${ }^{36}$

\section{THE ERA OF PLATELET GLYCOPROTEIN IIB/IIIA INHIBITORS}

The introduction of the IIb/IIIa antagonists has resulted in a further revolution in PCI. Their administration is mandatory in patients with acute coronary syndromes undergoing intervention. ${ }^{37}$ Debate persists about whether IIb/IIIa antagonists are necessary for every PCI procedure. ${ }^{38}$

Initial experience with these agents in the EPIC (evaluation of c7E3 Fab in the prevention of ischemic complications) trial demonstrated that administration of abciximab with standard dose heparin (10 000-12 000 U bolus plus 12 hour heparin infusion) and aspirin resulted in 35\% relative risk reduction at 30 days but a three fold increase in major bleeding complications $(10.6 \%$ in the treatment group $v 3.3 \%$ in the placebo group, $\mathrm{p}<0.001){ }^{39}$ Retrospective analysis suggested that administration of abciximab increased ACT by an average of 43 s compared with placebo. ${ }^{40}$

Both the subsequent EPILOG (evaluation of PTCA to improve long term outcome by c7E3 GP IIb/IIIa receptor blockade) and EPISTENT (evaluation of platelet GP IIb/IIIa inhibitor for stenting) trials used abciximab (bolus +12 hour infusion) and low dose heparin $(70 \mathrm{U} / \mathrm{kg}){ }^{41}{ }^{42}$ They demonstrated reduction in death, myocardial infarction, or repeat revascularisation compared with placebo at six months and no excess major bleeding complications.

Combined analysis of four abciximab trials shows lower ischaemic event rates across the entire range of ACT values. There is no $U$ shaped curve and in the presence of abciximab an ACT of $225 \mathrm{~s}$ appears to be equivalent to an ACT of $350-400 \mathrm{~s}$. Dose related bleeding risk is not significantly increased with abciximab compared with heparin alone until an ACT value of $375 \mathrm{~s}$ is exceeded ${ }^{28}$ Limited data exist on the effects of other glycoprotein IIb/IIIa inhibitors, but it appears that tirofiban and eptifibatide have similar effects upon thrombin generation, resulting in similar increases in ACT to those observed during abciximab treatment. ${ }^{43} 44$
HEPARIN ADMINISTRATION DURING SALVAGE PCI

There are currently no data to guide heparin dosing in patients undergoing rescue/salvage PCI after thrombolysis for acute myocardial infarction. Most of the studies and registry data predate the widespread use of glycoprotein IIb/IIIa antagonists and many predate the use of stents in this setting.

\section{LOW MOLECULAR WEIGHT HEPARIN AND PCI}

Low molecular weight heparin (LMWH) has become an established part of the treatment of acute coronary syndromes and venous thrombosis. Dose response is more predictable than UFH, long term administration is easier, and there is a theoretical advantage of no rebound thrombin generation resulting in a prothrombotic effect following discontinuation of UFH. ${ }^{45}$ The REDUCE trial demonstrated equivalent primary end points with UFH (10000 U bolus and 24 hour infusion) and reviparin (7000 U bolus and 24 hour infusion followed by subcutaneous administration for 28 days) ${ }^{47}$ Similarly the NICE (national investigators collaborating on enoxaparin) 1 pilot study in 60 patients undergoing PCI has demonstrated no difference in procedural outcomes using enoxaparin $1 \mathrm{mg} / \mathrm{kg}$ intravenously before $\mathrm{PCI}{ }^{48}$ A preliminary analysis of the non-randomised NICE 4 trial using enoxaparin $0.75 \mathrm{mg} / \mathrm{kg}$ as intravenous bolus plus standard doses of abciximab (bolus plus infusion) in 557 patients undergoing PCI has demonstrated a very low incidence of bleeding events compared with the abciximab plus low dose heparin group of the EPILOG trial $\left(0.6 \% v 2.7 \%\right.$, respectively).$^{49}$ Interestingly, a recent study of patients with acute coronary syndromes treated with enoxaparin showed that PCI can be performed safely without any additional heparin when it is performed within eight hours of subcutaneous injection. ${ }^{50}$

Therefore, despite potential theoretical advantages, the role of LMWH during PCI is unproven, particularly as in clinical practice there are likely to be concerns over monitoring its anticoagulant effect at the bedside. The ACT test is unaffected by LMWH and although algorithms are currently being developed to predict the likely response to LMWH, this difficulty in short term control may limit application of LMWH unless a dramatic effect on clinical outcomes can be shown. ${ }^{51}$

\section{DIRECT THROMBIN INHIBITORS IN PCI}

These agents have theoretical advantages as they inhibit both circulating and thrombin bound to clot. ${ }^{52}$ Monitoring of direct thrombin inhibitors is accomplished using the same ACT and aPTT guidelines as for UFH. Early studies in the pre-stent era failed to influence clinical practice as any advantages appeared modest. ${ }^{53} 54$ Further ongoing studies include CACHET (comparisons of abciximab complications with Hirulog for ischaemic events trial) and REPLACE (randomized evaluation in PCI linking Angiomax to reduced clinical events) with bivalirudin (and rescue glycoprotein IIb/IIIa administration) during PCI. ${ }^{55} 56$

\section{CONCLUSION}

UFH remains the standard anticoagulant in PCI, but a minimum required dose has not been defined when employing contemporary interventional techniques. Indeed it is possible to speculate that heparin may be unnecessary for some direct stent procedures, particularly if glycoprotein IIb/IIIa inhibitors are to be used or if LMWH has been administered recently.

There are no data to support routine administration of high doses of heparin at the initiation of every PCI procedure. The dose of heparin must be tailored to the clinical setting and the likely procedure to be undertaken. In patients with acute coronary syndromes undergoing PCI, target ACT may be as low as $200 \mathrm{~s}$ with adjunctive IIb/IIIa inhibitors and this can be achieved with a weight adjusted heparin bolus at 30-70 U/kg 
heparin. During salvage PCI, checking the ACT before the initiation of the intervention is recommended. With an ACT $>200 \mathrm{~s}$ heparin is probably unnecessary as this facilitates administration of glycoprotein IIb/IIIa inhibitors with their theoretical advantages over higher intensity anticoagulation with more heparin.

For the small number of elective PCI procedures where stents and glycoprotein IIb/IIIa inhibitors are unlikely to be used, weight adjusted heparin should be administered with a target ACT of 350-375 s at the end of the procedure. However, for the vast majority of elective PCI patients when stenting is planned, preloading with clopidogrel and aspirin allows a lower initial ACT target, and there are no convincing data that more than $50-70 \mathrm{U} / \mathrm{kg}$ or a fixed dose of $5000 \mathrm{U}$ heparin is necessary.

\section{Authors' affiliations}

G Niccoli, A P Banning, Department of Cardiology, John Radcliffe Hospital, Headington, Oxford, UK

\section{REFERENCES}

1 Rosenberg RD, Bauer KA. The heparin-antithrombin system: a natural anticoagulant mechanism. In: Colman RW, Hirsh J, Marder VJ, et al, eds. Hemostasis and thrombosis: basic principles and clinical practice, 3rd ed. Philadelphia: JB Lippincott Co, 1994:837-60

2 Topol E, Bonan R, Jewitt D, et al. Use of a direct antithrombin, hirulog, in place of heparin during coronary angioplasty. Circulation 1993:87:1622-9.

3 Grayburn P, Willard J, Brickner $M$, et al. In vivo thrombus formation on a guidewire during intravascular ultrasound imaging: evidence for inadequate heparinization. Cathet Cardiov Diagn 1991;23:141-3

4 Heras $M$, Chesebro J, Penny W, et al. Importance of adequate heparin dosage in arterial angioplasty in a porcine model. Circulation 1988;78:654-60.

5 Chesebro JH, Badimon L, Fuster V. Importance of antithrombin therapy during coronary angioplasty. J Am Coll Cardiol 1991;17/suppl B):96B-100B.

6 Oltrona L, Eisenberg P, Lasala J, et al. Association of heparin-resistant thrombin activity with acute ischemic complications of coronary interventions. Circulation 1996;94:2064-71

7 Pineo G, Hull R. Unfractionated and low molecular weight heparin: comparisons and current recommendations. Med Clin North Am 1998;82:587-99.

8 Young E, Podor TJ, Vemer T, et al. Induction of acute phase reaction increases heparin-binding proteins in plasma. Arterioscler Thromb Vasc Biol 1997; 17: 1568-74.

9 Hirsch J, Anand SS, Halperin JL, et al. Guide to anti-coagulant therapy: heparin. A statement for health care profesionals from the American Heart Association. Circulation 2001;103:2994-3018.

10 Becker RC. Hirudin-based anticoagulation strategies for patients with suspected heparin-induced thrombocytopenia undergoing percutaneous coronary interventions and bypass grafting. J Thromb Thrombolysis 2000;10(suppl 1):59-68.

11 Matthai WH Jr. Use of argatroban during percutaneous coronary interventions in patients with heparin-induced thrombocytopenia. Semin Thromb Hemost 1999;25(suppl 1):57-60.

12 Blumenthal RS, Carter AJ, Resar JR, et al. Comparison of bedside and hospital laboratory coagulation studies during and after coronary intervention. Cathet Cardiovasc Diagn 1995;35:9-17.

13 Avendano A, Ferguson JJ. Comparison of Hemochron and HemoTec activated coagulation time target values during percutaneous transluminal coronary angioplasty. J Am Coll Cardiol 1994:23:907-10.

14 Bowers J, Ferguson JJ, III. The use of activated clotting times to monitor heparin therapy during and after interventional procedures. Clin Cardiol 1994; 17:357-60.

15 Ferguson JJ. All ACTs are not created equal [editorial] Texas Heart Inst J 1992;19:1-3.

16 Dougherty K, Gaos C, Bush H, et al. Activated clotting times and activated partial thromboplastin times in patients undergoing coronary angioplasty who receive bolus doses of heparin. Cathet Cardiovasc Diagn 1992;26:260-3.

17 Owings JT, Pollock ME, Gosselin RC, et al. Anticoagulation of children undergoing cardiopulmonary bypass is overstimated by current monitoring techniques. Arch Surg 2000;135:1042-7.

18 Helft G, Bartolomeo P, Zaman AG, et al. The heparin management test: a new device for monitoring anticoagulation during coronary intervention. Thromb Res 1999;96:481-5.

19 Smith SC Jr, Dove JT, Jacobs AK, et al. ACC/AHA guidelines of percutaneous coronary interventions (revision of the 1993 PTCA guidelines) - executive summary. A report of the American College of Cardiology/American Heart Association task force on practice guidelines (committee to revise the 1993 guidelines for percutaneous transluminal coronary angioplasty). J Am Coll Cardiol 2001;15:2215-38.
20 Swanson N, Hogrefe K, Stephens A, et al. Current perspectives on British use of adjunctive therapies during coronary interventions. Int J Cardiol 2001;79:119-25

21 Knight CJ, Panesar M, Wilson DJ, et al. Increased platelet responsivenes following coronary stenting. Heparin as a possible aetiological factor in stent thrombosis. Eur Heart J 1998:19:1239-48.

22 Mabin TA, Holmes DR, Smith HC. Intracoronary thrombus: role in coronary occlusion complicating percutaneous transluminal coronary angioplasty. J Am Coll Cardiol 1985;5:198-202.

23 Waller BF, Fry ET, Peters TF, et al. Abrupt (<1 day), acute (< 1 week), and early $(<1$ month) vessel closure at the angioplasty site. Morphologic observations and causes of closure in 130 necropsy patients undergoing coronary angioplasty. Clin Cardiol 1996;19:857-68.

24 Bull B, Korpman R, Huse W, et al. Heparin therapy during extracorporeal circulation: problems inherent in existing heparin protocols. J Thorac Cardiovas Surg 1975;69:674-84.

25 Young J, Kisker C, Doty D. Adequate anticoagulation during cardiopulmonary bypass determined by activated clotting time and the appearence of fibrin monomer. Ann Thorac Surg 1978;26:231-40.

26 Ferguson J, Dougherty K, Gaos J, et al. Relation between procedural activated clotting time and outcome after percutaneous transluminal coronary angioplasty. J Am Coll Cardiol 1994;23:1061-5.

27 Narins CR, Hillegass WB Jr, Nelson CL, et al. Relation between activated clotting time during angioplasty and abrupt closure. Circulation 1996;93:667-71

28 Chew DP, Bhatt DL, Lincoff AM, et al. Defining the optimal activated clotting time during percutaneous coronary intervention: aggregate results from 6 randomized, controlled trials. Circulation 2001;103:961-6.

29 Xiao Z, Theroux P. Platelet activation with unfractionated heparin at therapeutic concentrations and comparisons with a low-molecular weight heparin and with a direct thrombin inhibitor. Circulation 1998:97:251-6.

30 Colombo A, Hall P, Nakamura S, et al. Intracoronary stenting without anticoagulation accomplished with intravascular ultrasound guidance. Circulation 1995;91:1676-88

31 Muller C, Buttner H, Petersen J, et al. A randomised comparison of clopidogrel and aspirin versus ticlopidine and aspirin after the placement of coronary-artery stents. Circulation 2000;101:590-3.

32 Boccara $A$, Benamer $\mathrm{H}$, Juliard JM, et al. A randomized trial of a fixed high dose vs a weight-adjusted dose of intravenous heparin during coronary angioplasty. Eur Heart J 1997; 18:631-5

33 Koch KT, Piek JJ, de Winter RJ, et al. Safety of low dose heparin in elective coronary angioplasty. Heart 1997:77:517-22.

34 Koch KT, Piek Jj, de Winter RJ, et al. Two hour ambulation after coronary angioplasty and stenting with $6 \mathrm{~F}$ guiding catheters and low dose heparin. Heart 1999;81:53-6.

35 Kaluski E, Krakover R, Cotter G, et al. Minimal heparinization in coronary angioplasty - how much heparin is really warranted? Am J Cardiol 2000:85:953-6.

36 Godon P, Rioufol G, Finet G, et al. Efficacy and safety of low-dose heparin $(30 \mathrm{IU} / \mathrm{kg})$ during coronary angioplasty. Arch Mal Coeur Vaiss 2001;94:984-8.

37 National Institute for Clinical Excellence. Guidance on the use of glycoprotein Ilb-Illa inhibitors in the treatment of acute coronary syndromes. National Institute for Clinical Excellence technology appraisal guidance. Number 12, September 2000: 1 .

38 Knight CJ. National Institute for Clinical Excellence guidance: too NICE to glycoprotein Ilb/Illa inhibitors? Heart 2001;85:481-3

39 EPIC Investigators. Use of a monoclonal antibody directed against the platelet glycoprotein Ilb/Illa receptor in high-risk coronary angioplasty. $\mathrm{N}$ Engl J Med 1994;330:956-61

40 Moliterno DJ, Califf RM, Aguirre FV, et al. Effect of platelet glycoprotein $\mathrm{llb} / \mathrm{llla}$ integrin blockade on activated clotting time during percutaneous transluminal coronary or directional atherectom (the EPIC trial). Evaluation of c7E3 Fab in the prevention of ischemic complications trial. Am J Cardiol 1995;75:559-62.

41 EPILOG Investigators. Platelet glycoprotein Ilb/llla receptor blockade and low-dose heparin during percutaneous coronary revascularization. $N$ Engl J Med 1997;336:1689-96.

42 EPISTENT Investigators. Randomized placebo-controlled and balloon-angioplasty-controlled trial to assess safety of coronary stenting with use of platelet glycoprotein Ilb/Illa blockade. Lancet 1998;352:87-92.

43 Ambrose JA, Doss R, Geagea JPM, et al. Effects on thrombin generation of the platelet glycoprotein Ilb/llla inhibitors abciximab versus tirofiban during coronary intervention. Am J Cardiol 2001;87:1231-3.

44 Mandak JS, Blankenship JC, Gardner LH, et al. Modifiable risk factors for vascular access site complications in the impact II trial of angioplasty with versus without eptifibatide. J Am Coll Cardiol 1998;31:1518-24.

45 Turpie AGG. Successors to heparin: new antithrombotic agents. Am Heart J 1997;134:S71-7.

46 Antman EM, Handin R. Low-molecular weight heparins. An intriguing new twist with profound implications. Circulation 1998;98:87-9.

47 Karsch KR, Preisack MB, Baildon R, et al. Low molecular weight heparin (reviparin) in percutaneous transluminal coronary angioplasty. Results of a randomized, double-blind, unfractionated heparin and placebo controlled, multicenter trial (REDUCE trial). Reduction of restenosis after PTCA, early administration of reviparin in a double-blind unfractionated heparin and placebo-controlled evaluation. J Am Coll Cardiol 1996;28:1437-43.

48 Grines CL. Anticoagulation requirements for coronary interventions and the role of low molecular weight heparins. J Invas Cardiol $1999 ; 11: 7 A-12 A$. 
49 Kereiakes DJ, Fry E, Matthai W, et al. Safety of enoxaparin-abciximab combination for percutaneous coronary intervention: preliminary results of the NICE 4 trial [abstract]. Am J Cardiol 1999;84:67P

50 Collet JPh, Montalescot G, Lison L, et al. Percutaneous coronary intervention after subcutaneous enoxaparin pre-treatment in patients with unstable angina pectoris. Circulation 2001;103:658-63.

51 Greiber S, Weber U, Galle J. Activated clotting time is not a sensitive parameter to monitor anticoagulation with low molecular weight heparin in hemodialysis. Nephron 1997;76:15-19.

52 Antman EM. The search for replacement for unfractionated heparin. Circulation 2001;103:2310-14.
53 Serruys PW, Herrman JPR, Simon R, et al for the HELVETICA Investigators. A comparison of hirudin with heparin in the prevention of restenosis after coronary angioplasty. N Engl J Med 1995;333:757-63. 54 Bittl JA, Strony J, Brinker JA, et al for the HIRULOG Angioplasty Study Investigators. N Engl J Med 1995:333:764-9.

55 Topol EJ. Evolution of improved antithrombotic and antiplatelet agents: genesis of the comparison of abciximab complications with hirulog (and back-up abciximab) events trial (CACHET). Am J Cardiol 1998;82:63P-68P

56 Bates ER. Bivalirudin for percutaneous coronary intervention and in acute coronary syndromes. Current Cardiology Reports 2001;3:348-54.

\section{IMAGES IN CARDIOLOGY}

\section{ST segment monitoring of coronary reperfusion}

A

58 year old man with no previous cardiac history presented to the coronary care unit with an acute inferoposterior myocardial infarction. Fibrinolysis with alteplase (rt-PA) was started within two hours following symptom onset. Reperfusion was monitored with a 12 lead ST monitor (Surveyor, Mortara, Italy). After a transient recovery and re-elevation (caused by atropine administration), the ST segment repeatedly (16 times) waxed and waned, over a fixed cycle of about four minutes (see lead D3 ST trend on right side of panel). Cyclic oscillations became progressively wider, despite the mean ST segment value progressively decreasing. The phenomenon was exacerbated after glyceryl trinitrate (TNG) infusion, that was thereafter re-introduced at a dose of up to $300 \mu \mathrm{g} / \mathrm{min}$. After 90 minutes, the ST segment level in lead D3 recovered from $0.5 \mathrm{mV}$ to $0.16 \mathrm{mV}$. The patient's chest pain gradually diminished and disappeared with no correlation with ECG. Troponin I peak $(25.6 \mathrm{ng} / \mathrm{ml})$ was recorded 10 hours after symptoms onset, and then rapidly decreased. The patient was discharge after five days after following a normal clinical course.

The nature of this intermittent closing and opening of the infarct coronary artery is not known. The presence of periodism and its relation with nitrate withdrawal and readministration should indicate a vasomotor mechanism, rather than a thrombotic phenomenon. This case supports the superiority of continuous ST segment monitoring over single ECGs in assessing ST segment resolution during fibrinolysis.

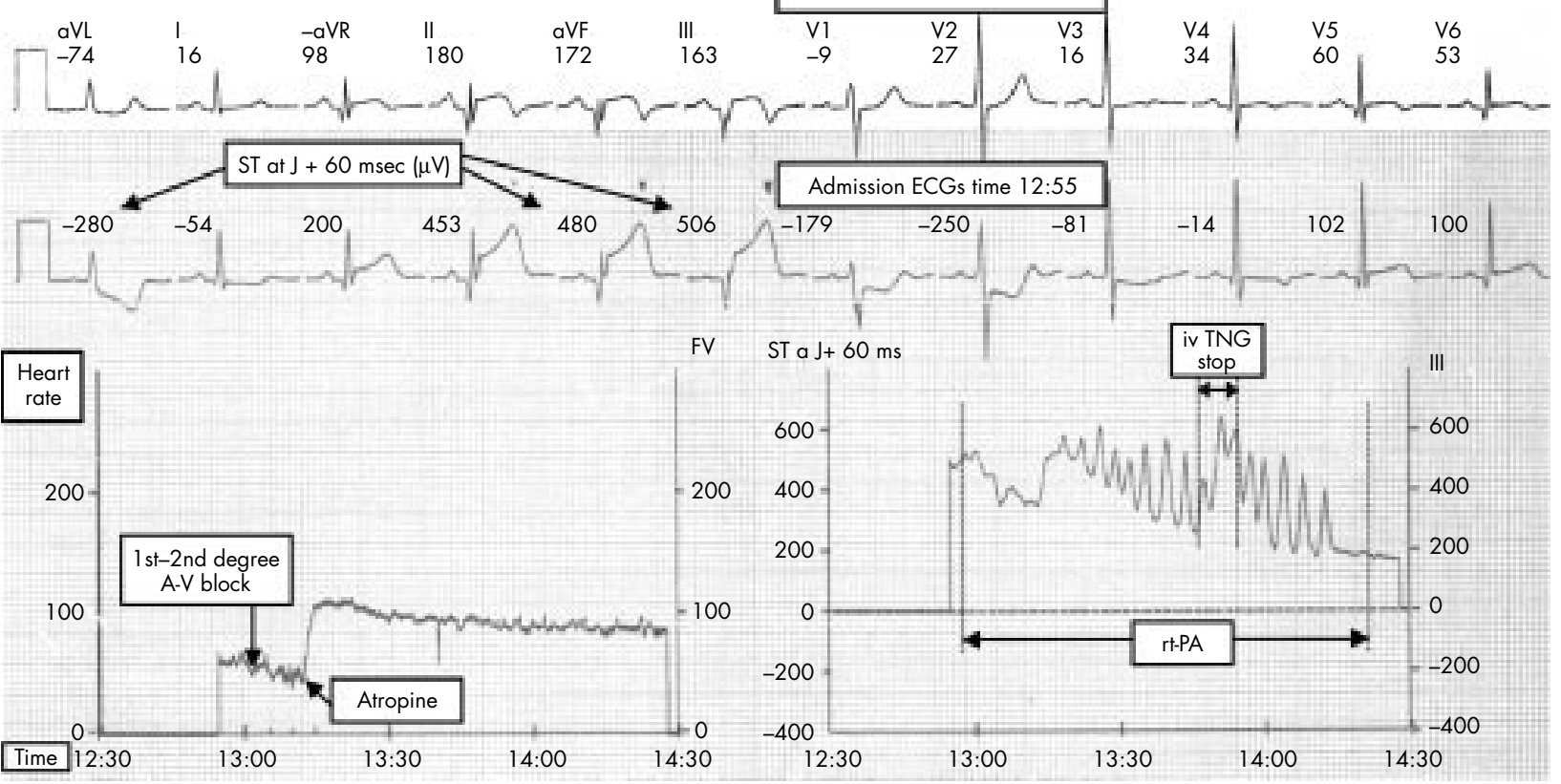

